\title{
AN ANALYSIS OF ORIENTATION CAGE FIELD DATA - A CASE STUDY OF HEADINGS OF THE BLACKCAP, SYLVIA ATRICAPILLA, AT THE BUKOWO/KOPAŃ RINGING SITE IN POLAND
}

\author{
Przemysław Busse
}

\begin{abstract}
Busse P. 2020. An analysis of orientation cage field data - a case study of headings of the Blackcap, Sylvia atricapilla, at the Bukowo/Kopan ringing site in Poland. Ring 42: 51-74. One of the most effective methods of studying the migratory patterns of nocturnal passerine migrants is the use of orientation cages as a supplementary procedure at ringing sites. The most comprehensive studies using orientation cages (Busse's Flat Orientation Cage) were conducted within the SEEN network (SE European Bird Migration Network), with more than 43,000 tests performed at more than 40 ringing sites in autumn. A number of papers were published based on these data, presenting an overall pattern of passerine migration over SE Europe-Middle East-NE Africa. For more detailed analyses, it was first necessary to solve some methodical problems within case studies. The current work presents details for discussion based on data from 1338 tests of Blackcaps performed during the years 1995-2010 at a single ringing station, Bukowo/Kopań, located on the Polish Baltic coast. The birds were tested according to the standard methodology of the SEEN network (Busse 2000). The problems investigated were (1) the repeatability of heading patterns obtained in different years, (2) the linearity of the estimated arrival and departure headings, and (3) quantitative aspects of the results in the description of the heading pattern when migratory groups are found.

It was determined that (1) yearly heading patterns were generally coherent and could be analysed as uniform case data; (2-1) the hypothesis that the arrival/departure heading axes are generally linear is accurate to within about one $10^{\circ}$ sector, at least in the case of the Blackcap. This is coherent with impressions from other known data sets, but does not mean that the rule always applies to all species at every location on the migration route. In the future, this problem should be studied on a more detailed scale. It was further established that (2-2) estimating arrival and departure headings makes it possible to define migratory groups (populations) passing the study site. The direct heading estimation procedure seems to be more sensitive in identifying migratory groups than the calculation procedure. Moreover, (3-1) the calculation procedure makes it possible to estimate some quantitative properties of headings of migratory groups and define some interesting, though preliminary, number patterns of local migratory patterns; (3-2) the number relations between birds demonstrating the arrival and departure headings of the migratory group seem to be an interesting parameter for study on the distance of migration of groups within a species and, possibly, between species. This is another interesting problem that
\end{abstract}


cage tests could be used to solve in the future. Finally, (3-3) knowledge about trends of individual populations passing the defined site becomes accessible only using analysis of data from orientation cages. The estimated quantitative indices discussed above could be helpful in presenting the general migratory pattern of the species on a geographical scale.

P. Busse, Bird Migration Research Foundation, Przebendowo 3, 84-210 Choczewo, Poland; e-mail: busse@wbwp-fund.eu

Keywords: orientation cage, headings pattern, methods, autumn migration, passerines, Blackcap, Sylvia atricapilla, Poland

\section{INTRODUCTION}

One of the most effective methods of studying the migratory patterns of nocturnal passerine migrants is the use of orientation cages as a supplementary procedure at ringing sites - both permanent professional bird stations and temporary camps organized by ringers, local bird clubs, etc. Orientation cage studies began primarily at laboratories as a tool for research on the orientation cues guiding birds during nocturnal seasonal migration (e.g. Kramer 1949). The first designs of cages were rather heavy and confined to laboratory conditions, e.g. in a planetarium (e.g. Sauer 1957), or required an electric power source for operation. The laboratory protocols usually depended on hand-rearing of experimental birds or at least handling in aviary conditions. The studies were labour-intensive and time-consuming, and thus were carried out on limited numbers of birds. Early trials of the method in field conditions were rather scarce (Evans 1968) and covered small numbers of individuals. However, they drew attention to a new aspect of the results: instead of suggesting cues directing the individual (guiding in a defined direction), the results provided information about the actual direction chosen by the individual tested in that geographic location. Thus, individuals of the same species could show different preferred directions according to the location of the site within the migration pattern of the species. As a result, students obtained information not on 'orientation cues', but on the 'local heading' of the bird. The new aspect of the studies forced the testing procedure to be simplified and not dependent on laboratory facilities or a source of electricity. The first step in that direction was a simple model of the orientation cage called 'Emlen's funnel'. This was a vertical conical tube with a round netted top, a sloped paper wall, and an inkpad on the bottom (Emlen and Emlen 1966). The bird tried to escape through the top by hopping and fluttering inside, but because of the net it slipped down along the wall and fell onto the inkpad. Traces of ink from the bird were left on the wall in the direction in which the bird had jumped. The pattern of the directions was evaluated visually based on the intensity of the ink traces. The method was later improved by removing the inkpad and replacing the ordinary paper wall with correction paper (used at that time to correct text produced with a mechanical typewriter). The traces of the bird's activity were scratches on the correction paper that could be counted, although it was sometimes very difficult to count them exactly. However, the method was still time- 
consuming, especially since traditionally one-hour testing at night was standard. Then, a further step of simplification was introduced - the construction of a flat orientation cage called 'Busse's flat cage' (Busse 1995). In the standard procedure of the method, a testing time of only 10 minutes during the daytime was established (allowing six birds to be tested per hour), and a new evaluation method was introduced (Busse and Trocińska 1999). Since that time, more than 43,000 tests from nocturnal migrants have been conducted in autumn at more than 40 European ringing sites, mainly by Operation Baltic and SEEN (SE European Bird Migration Network) (Busse 2019) and more than 20,000 in spring. The compatibility of results from Emlen's Funnel and Busse's Flat Cage has been studied and confirmed (a few papers, e.g. Nowakowski and Malewska 1999, Zehtindijev et al. 2003, Ożarowska and Yosef 2004, summarized in Busse 2017). The development of evaluation of test data was discussed in a paper by Busse (2018), and the general pattern of nocturnal migration of passerines (all species included) based on the collected data was presented in a subsequent paper by Busse (2019). This very general estimation presented a few problems to be solved in further studies. First, it was found that at each location studied it is possible to define several migration streams directed towards different destinations. They usually are highly coherent over wide territories, and thus they reflect different species/population patterns. The fundamental question is whether these are the result of species-level differentiation or population differences within the species. That means that there is a need to go deeper into single-species migration patterns. First, however, we need to know some details that influence the shape of the migration patterns.

It is well known that most single individuals show multimodal headings in the cage (e.g. Busse 1995; Busse and Trocińska 1999; Muś 2005, 2008; Ożarowska and Muś 2008) and the same applies when we combine these headings into group/sample headings at the test site. In most cases, especially in group heading patterns, the heading axes are found to be located more or less on opposite sides of the wind rose, and are interpreted as 'input' (arrival) and 'output' (departure) headings. Distributions in the group headings are differentiated as to 'power' within yearly samples as well as between groups tested in different years.

The first task of this paper is to check whether the headings are actually linear (creating coherent axes), and the second is to determine to what extent we can estimate the size of the groups heading within different axes (streams of migration), and how accurate our estimations of relative numbers of individuals caught at a single study site and migrating as different populations could be. These problems will be discussed based on the example of the Blackcap, Sylvia atricapilla, at the Bukowo/ Kopań Polish ringing station (Operation Baltic/SEEN). That station collected the longest orientation data set (1995-2010), and the Blackcap was one of the most commonly tested bird species there.

\section{MATERIAL AND METHODS}

The material was collected at the Bukowo/Kopan Operation Baltic station $\left(54^{\circ} 28^{\prime} \mathrm{N}, 16^{\circ} 25^{\prime} \mathrm{E}\right)$ located on the Baltic coast, in a strip of pine forest bordering on wet meadows, with some willow bushes and reed-beds of the Kopań Lake. From 1995 
to 2010, throughout the autumn migration period (August-November), 1338 Blackcaps were tested (see Table 1 for yearly numbers). Birds were caught using mist-nets, sexed/aged, measured (wing length, tail length, and wing formula), scored for fatness, and weighed according to Operation Baltic/SEEN standards (Busse 2000). Individuals were immediately (within 2 hours) tested in Busse's Flat Orientation Cage (Busse 1995, 2000), placed in a wide, open meadow. The test lasted 10 minutes. The total number of Blackcaps caught was much higher than the number tested, as individuals for testing were taken randomly, mainly according to the availability of manpower for running tests.

Table 1

Yearly locations of arrival and departure group heading vectors within a 32-sector wind-rose according to the estimation procedure (numbers of sectors counted clockwise from the north). The difference between the axial arrival/departure positions of vectors is given as the number of sectors clockwise. $N$ - number of individuals tested.

\begin{tabular}{|c|c|c|c|c|c|}
\hline Year & $N$ & Group & Arrival & Departure & Difference \\
\hline \multirow{4}{*}{1995} & \multirow{4}{*}{20} & $R E D$ & 7 & 25 & 2 \\
\hline & & $B L U E$ & 3 & 19 & 0 \\
\hline & & ORANGE & 31 & 14 & 1 \\
\hline & & YELLOW & & & \\
\hline \multirow{4}{*}{1996} & \multirow{4}{*}{56} & $R E D$ & & 23 & \\
\hline & & $B L U E$ & 3 & 19 & 0 \\
\hline & & ORANGE & 30 & 15 & -1 \\
\hline & & YELLOW & & 10 & \\
\hline \multirow{4}{*}{1997} & \multirow{4}{*}{117} & $R E D$ & 7 & & \\
\hline & & $B L U E$ & 3 & 21 & \\
\hline & & ORANGE & & 15 & \\
\hline & & YELLOW & 29 & 11 & 2 \\
\hline \multirow{4}{*}{1999} & \multirow{4}{*}{146} & $R E D$ & & & \\
\hline & & $B L U E$ & 3 & 17 & 2 \\
\hline & & ORANGE & 31 & & \\
\hline & & YELLOW & 27 & 11 & 1 \\
\hline \multirow{4}{*}{2000} & \multirow{4}{*}{52} & $R E D$ & 7 & 21 & 2 \\
\hline & & $B L U E$ & 3 & & \\
\hline & & ORANGE & 31 & 15 & 0 \\
\hline & & YELLOW & 26 & 11 & \\
\hline \multirow{4}{*}{2001} & \multirow{4}{*}{214} & $R E D$ & 7 & & \\
\hline & & $B L U E$ & 3 & 21 & -2 \\
\hline & & ORANGE & 31 & 15 & 0 \\
\hline & & YELLOW & 27 & 12 & -1 \\
\hline \multirow{4}{*}{2002} & \multirow{4}{*}{201} & $R E D$ & 7 & 22 & 1 \\
\hline & & $B L U E$ & & & \\
\hline & & ORANGE & 31 & & \\
\hline & & YELLOW & 27 & 11 & 0 \\
\hline
\end{tabular}




\begin{tabular}{|c|c|c|c|c|c|}
\hline Year & $N$ & Group & Arrival & Departure & Difference \\
\hline \multirow{4}{*}{2004} & \multirow{4}{*}{118} & $R E D$ & & 23 & \\
\hline & & $B L U E$ & 5 & 19 & 2 \\
\hline & & ORANGE & & & \\
\hline & & YELLOW & 27 & 11 & 0 \\
\hline \multirow{4}{*}{2005} & \multirow{4}{*}{36} & $R E D$ & 8 & & \\
\hline & & $B L U E$ & 3 & & \\
\hline & & ORANGE & 31 & 17 & -2 \\
\hline & & YELLOW & 27 & & \\
\hline \multirow{4}{*}{2006} & \multirow{4}{*}{92} & $R E D$ & 8 & 23 & 1 \\
\hline & & $B L U E$ & 5 & 19 & 2 \\
\hline & & ORANGE & 1 & & \\
\hline & & YELLOW & 29 & 11 & 2 \\
\hline \multirow{4}{*}{2007} & \multirow{4}{*}{100} & $R E D$ & & 23 & \\
\hline & & $B L U E$ & 5 & 18 & 3 \\
\hline & & ORANGE & & 13 & \\
\hline & & YELLOW & 27 & 9 & 2 \\
\hline \multirow{4}{*}{2008} & \multirow{4}{*}{97} & $R E D$ & 7 & 25 & -2 \\
\hline & & $B L U E$ & 2 & 21 & -3 \\
\hline & & ORANGE & & & \\
\hline & & YELLOW & 29 & 11 & 2 \\
\hline \multirow{4}{*}{2010} & \multirow{4}{*}{89} & $R E D$ & 7 & 21 & 2 \\
\hline & & BLUE & & & \\
\hline & & ORANGE & & 16 & \\
\hline & & YELLOW & 30 & & \\
\hline
\end{tabular}

Basic field data processing has been presented and discussed in detail by Busse (2017). The procedure used assumed the multimodality of distributions at both levels of evaluation: individual bird and group distribution of headings. The individual bird level was based on actual numbers of scratches made by the bird in eight sectors of the cage. The individual distributions of scratches were processed in ORIENT 4.6 software, which gave the individual heading pattern: no significant heading according to the chi-square test, or from one to a maximum of four vectors, which were assigned to one of 16 sectors of the wind-rose. Each vector had its own 'power', i.e. a percentage share in the total number of scratches. The individual heading pattern can be presented as vectors (direction and length illustrating the 'power') on a wind-rose panel. This presentation is rarely used, as the main goal of testing is to obtain the group distribution of headings. At the group level, vectors of all individuals included in a defined sample were added in sectors. The group headings distribution was the distribution of percentage shares (indices of the number of headings) of the above-mentioned sector sums in the total sum of powers. Group distributions are usually presented as polygons in radar graphs on the wind-rose panel (Fig. 1). This was the starting material for this analysis, which is mainly a methodical case analysis of the data on the Blackcap, as an example, collected at a single ringing station over several years. 
The general pattern of headings of all individuals tested in the study and evaluated as explained above is shown in Figure 1. According to the procedure of estimation of the main headings, described in detail by Busse (2018), the distribution was interpreted as several estimated headings presenting 'input' (arrival) and 'output' (departure) heading directions.

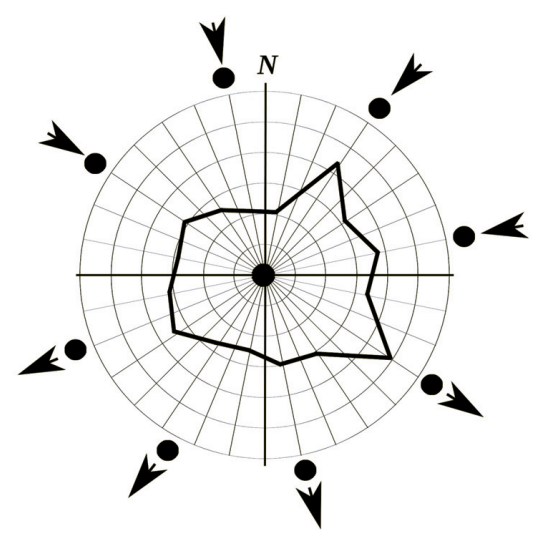

Fig. 1. Total distribution of headings of Blackcaps at the Bukowo/Kopań ringing site (polygon inside the wind-rose). Dots outside the wind-rose - estimated local hidden distributions; arrows directions of migration in autumn (arrivals from the north, departures to the south).

The first problem to be solved within the analysis is to determine how far these estimated patterns are coherent at the study site over the years. Such an analysis had been performed for the general (multispecies) pattern of headings at the same ringing station as in this case study (Fig. 2 after Busse 2019). In the source paper of this figure, it was concluded that the concentrations of yearly headings were sufficiently in agreement that the pattern could be said to significantly confirm the total heading directions. The same procedure was later performed on the Blackcap data (see Fig. 2 in the present work).

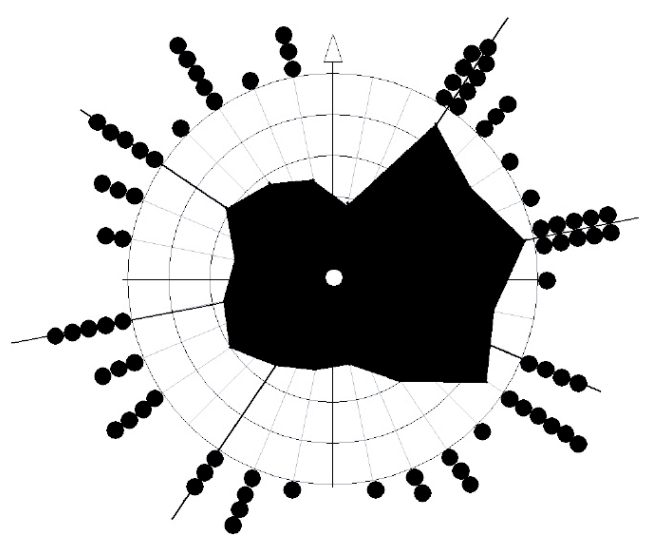

Fig. 2. Distributions of yearly headings (dots) of migrants studied at the Bukowo/Kopań ringing site (1995-2010). After Fig. 6 in the paper by Busse (2019). 
The second problem to be investigated is the suspected axiality of arrival and departure headings, and at the same time whether potential axes can be interpreted more generally within a general migration pattern of passerines over the wider area, as presented in the earlier paper (Busse 2019) on the migration pattern, as shown in Figure 3. Numbers of birds demonstrating arrival headings (opposite to the autumn migration directions) in the orientation cage (e.g. Formella and Busse 2002, Ściborska and Busse 2004) are well known to be highly differentiated from axial or nearly axial departure directions. This suggests that a third problem could be studied in parallel - how to quantify the numbers of birds heading according to different axes/population streams shown on the maps.

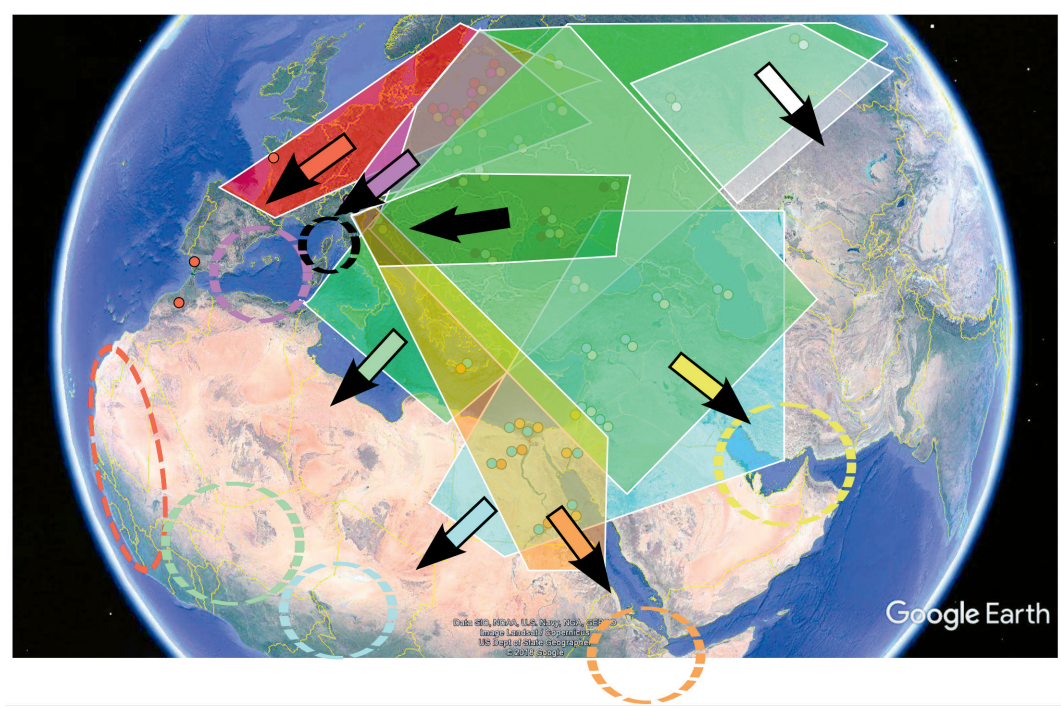

Fig. 3. General estimated patterns of passerine migration over Europe. After Fig. 18 in the paper by Busse (2019).

Due to the properties of the field method - an orientation cage wind-rose divided into only eight sectors - the heading vectors will not be very precise, as to either direction or length. Previous estimations suggest that the level of precision of directions determined using estimation procedures can be plus/minus $6-11^{\circ}$, which means one of 32 rose-wind sectors. The estimation procedure, after Busse (2019), takes into account mainly the local maxima of the polygon of distribution of headings (Fig. 1). For a more quantitative determination of the heading direction (and its 'power' - the number index of the heading vector) we can use not only the local maximum value in the result vector calculation, but also those closely bordering on it (minus one and plus one sector values), and sum up these three values. The result vector will be more precise than previously, and we will have some information about its power (share of the index in the total distribution). The power values will still be estimated, but they will hereafter be referred to as 'calculated'. This term here is not the same as the term 'calculated' as used in an earlier paper (Busse 2018) to discuss the calculation procedure used by Ożarowska et al. 2013. Their calculations are more precise, but are still 
based on the same raw field data originating from the same testing device, so the results from both versions of calculations must be treated as approximate rather than exact, despite being reached following sophisticated Bayesian processing. However, in any general bird migration study the level of precision reached here is high enough for a discussion of migration patterns on a continental scale.

In all figures, colours are used according to the classification of migration streams presented in Figure 3 - after Fig. 18 in Busse (2019) - except that the stream shown there as VIOLET is shown as BLUE here. Thus, the RED stream is heading far westwards (traditionally referred to as the Atlantic Flyway), the BLUE stream towards the western Mediterranean, ORANGE directly to eastern Africa, and YELLOW towards the Middle East/Arabian Peninsula (the last two together are usually referred to as the SE European Flyway).

\section{RESULTS AND DISCUSSION}

\section{Axiality of arrival/departure tracks}

The general pattern of Blackcap headings at the station in the years 1995-2010 is shown in Figure 4. The main headings found using the simpler 'estimated' procedure and the 'calculated' procedure are compared. The calculated departure headings are compared with the arrival headings, and deviations from linearity are indicated. The $R E D$ group tracks are perfectly linear, while the YELLOW group departure heading is shifted by one sector of the 32-sector wind-rose. For the BLUE group, the departure heading is not found within the calculation procedure, while for the ORANGE group the arrival track was not visible. In this general comparison, the axes drawn according to the estimation procedure are more exactly linear, and all groups show coherent arrival-departure directions. This suggests that for study of the linearity problem, the

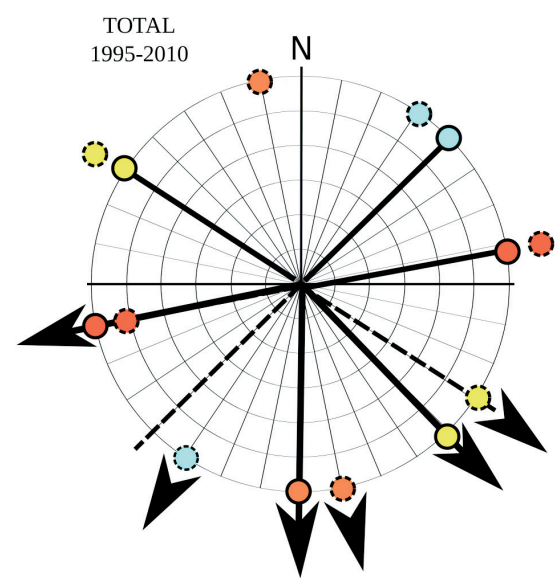

Fig. 4. Axes of headings of different migratory groups (visualized by colours - RED, BLUE, ORANGE and YELLOW throughout the text and figures) estimated directly from the total distribution of headings as shown in Fig. 1 (broken-line circles) and using the calculation procedure (solid-line circles). 
simple estimation procedure is more exact, while the calculation procedure may obscure the pattern by hiding the headings of less numerous groups.

Yearly heading patterns from the estimation procedure are listed in Table 1, while these determined using calculations are presented in Table 2. Headings in Table 1 are defined by the number of the sector they belong to, and heading deviations are expressed as the number of sectors between the arrival track and the departure track. In Table 2, both directions and deviations of headings are expressed in sectors and degrees. A graphic presentation of yearly results can be found in Figure 5. Some variation could be found from year to year, for various reasons, such as weather conditions, the composition of migration waves according to the number of birds following various streams of migration, population size dynamics of different groups of migrants, etc. These have been discussed in a few earlier papers (e.g. Formella and Busse 2002, Ściborska and Busse 2004, Adamska and Filar 2005).

Table 2

Yearly locations of arrival and departure group heading vectors within a 32-sector wind-rose according to the estimation procedure (numbers of sectors counted clockwise from the north). The difference between the axial arrival/departure positions of vectors is given as the number of sectors clockwise. $N$ - number of individuals tested.

\begin{tabular}{|c|c|c|c|c|c|c|c|c|}
\hline \multirow{2}{*}{ Year } & \multirow{2}{*}{$N$} & \multirow{2}{*}{ Group } & \multicolumn{2}{|c|}{ Arrival } & \multicolumn{2}{|c|}{ Departure } & \multicolumn{2}{|c|}{ Difference } \\
\hline & & & Degrees & Sectors & Degrees & Sectors & Degrees & Sectors \\
\hline \multirow{4}{*}{1995} & \multirow{4}{*}{20} & $R E D$ & & & 270 & 17.8 & & \\
\hline & & $B L U E$ & 40 & 20.1 & 223 & 19.9 & 3 & -0.2 \\
\hline & & ORANGE & 359 & 15.9 & 168 & 14.9 & -11 & -1.0 \\
\hline & & YELLOW & 293 & 10.1 & & & & \\
\hline \multirow{4}{*}{1996} & \multirow{4}{*}{56} & $R E D$ & & & & & & \\
\hline & & $B L U E$ & 45 & 20.0 & 226 & 20.0 & 1 & 0.0 \\
\hline & & ORANGE & & & 181 & 16.0 & & \\
\hline & & YELLOW & 304 & 11.0 & 123 & 11.0 & -1 & 0.0 \\
\hline \multirow{4}{*}{1997} & \multirow{4}{*}{117} & $R E D$ & 88 & 23.8 & 248 & 22.1 & -20 & -1.7 \\
\hline & & $B L U E$ & 46 & 20.1 & & & & \\
\hline & & ORANGE & 349 & 15.0 & 179 & 15.9 & 10 & 0.9 \\
\hline & & YELLOW & & & 136 & 12.1 & & \\
\hline \multirow{4}{*}{1999} & \multirow{4}{*}{146} & $R E D$ & & & & & & \\
\hline & & $B L U E$ & 45 & 20.0 & 202 & 18.0 & -23 & -2.0 \\
\hline & & ORANGE & & & & & & \\
\hline & & YELLOW & 314 & 11.9 & 134 & 11.9 & 0 & 0.0 \\
\hline \multirow{4}{*}{2000} & \multirow{4}{*}{52} & $R E D$ & 89 & 23.9 & 247 & 21.9 & -22 & -2.0 \\
\hline & & $B L U E$ & 46 & 20.1 & & & & \\
\hline & & ORANGE & 350 & 15.1 & & & & \\
\hline & & YELLOW & 304 & 11.0 & 146 & 13.0 & 22 & 2.0 \\
\hline \multirow{4}{*}{2001} & \multirow{4}{*}{214} & $R E D$ & 89 & 23.9 & 248 & 22.0 & -21 & -1.9 \\
\hline & & $B L U E$ & 45 & 20.0 & & & & \\
\hline & & ORANGE & & & & & & \\
\hline & & YELLOW & 315 & 12.0 & 146 & 13.0 & 11 & 1.0 \\
\hline
\end{tabular}


Table 2. cont.

\begin{tabular}{|c|c|c|c|c|c|c|c|c|}
\hline \multirow{2}{*}{ Year } & \multirow{2}{*}{$N$} & \multirow{2}{*}{ Group } & \multicolumn{2}{|c|}{ Arrival } & \multicolumn{2}{|c|}{ Departure } & \multicolumn{2}{|c|}{ Difference } \\
\hline & & & Degrees & Sectors & Degrees & Sectors & Degrees & Sectors \\
\hline \multirow{4}{*}{2002} & \multirow{4}{*}{201} & $R E D$ & 79 & 23.0 & 260 & 23.1 & 1 & 0.1 \\
\hline & & $B L U E$ & & & & & & \\
\hline & & ORANGE & & & & & & \\
\hline & & YELLOW & 326 & 13.0 & 145 & 12.9 & -1 & -0.1 \\
\hline \multirow{4}{*}{2004} & \multirow{4}{*}{118} & $R E D$ & 67 & 22.0 & & & & \\
\hline & & $B L U E$ & & & 225 & 20.0 & & \\
\hline & & ORANGE & & & & & & \\
\hline & & YELLOW & 304 & 11.0 & 135 & 12.0 & 11 & 1.0 \\
\hline \multirow{4}{*}{2005} & \multirow{4}{*}{36} & $R E D$ & 81 & 23.2 & 259 & 23.1 & -2 & -0.1 \\
\hline & & $B L U E$ & 226 & 20.1 & & & & \\
\hline & & ORANGE & 360 & 16.0 & 202 & 18.0 & 22 & 2.0 \\
\hline & & YELLOW & 316 & 12.0 & 113 & 4.9 & -23 & -7.1 \\
\hline \multirow{5}{*}{2006} & \multirow{5}{*}{92} & RED & 78 & 22.9 & & & & \\
\hline & & $B L U E$ & & & 225 & 20.0 & & \\
\hline & & ORANGE & & & & & & \\
\hline & & YELLOW & 293 & 9.1 & 135 & 12.0 & 22 & 2.9 \\
\hline & & YELLOW & 337 & 14.0 & & & & \\
\hline \multirow{4}{*}{2007} & \multirow{4}{*}{100} & $R E D$ & 79 & 20.3 & 270 & 24.0 & 11 & 3.7 \\
\hline & & $B L U E$ & & & 214 & 19.0 & & \\
\hline & & ORANGE & & & 157 & 13.9 & & \\
\hline & & YELLOW & 305 & 11.1 & 123 & 10.9 & -2 & -0.2 \\
\hline \multirow{4}{*}{2008} & \multirow{4}{*}{97} & $R E D$ & 81 & 23.7 & 259 & 23.1 & -2 & -0.6 \\
\hline & & $B L U E$ & 34 & 19.0 & & & & \\
\hline & & ORANGE & & & 180 & 16.0 & & \\
\hline & & YELLOW & 290 & 9.8 & 134 & 11.9 & 24 & 2.1 \\
\hline \multirow{4}{*}{2010} & \multirow{4}{*}{89} & $R E D$ & 80 & 23.1 & & & & \\
\hline & & $B L U E$ & & & 237 & 21.1 & & \\
\hline & & ORANGE & & & 191 & 17.0 & & \\
\hline & & YELLOW & 327 & 13.0 & 123 & 10.9 & -24 & -2.1 \\
\hline
\end{tabular}

Despite some variability, the headings pattern seems to be consistent enough within the study period, as shown in Figure 6. This seems to be true for both the estimated and calculated procedures. An overall pattern of headings common for all the years is presented in Figure 7, where smoothing of yearly heading numbers is shown in linear form. Table 3 summarizes the results of the determination of headings reached using different variants of the analysis. Sectors 4 and 5 contain the arrival headings of the $B L U E$ group (sector 4 - total and yearly estimations; sector 5 yearly, calculated), while sector 20 contains the total and yearly estimated departure headings of this group. RED group arrivals are located in the 8 th sector by all variants of analysis, while departure headings are located differently (sectors 22-24), probably due to variation in the numbers of birds belonging to BLUE and RED groups in different years and the formation of mixed peaks in distributions. 

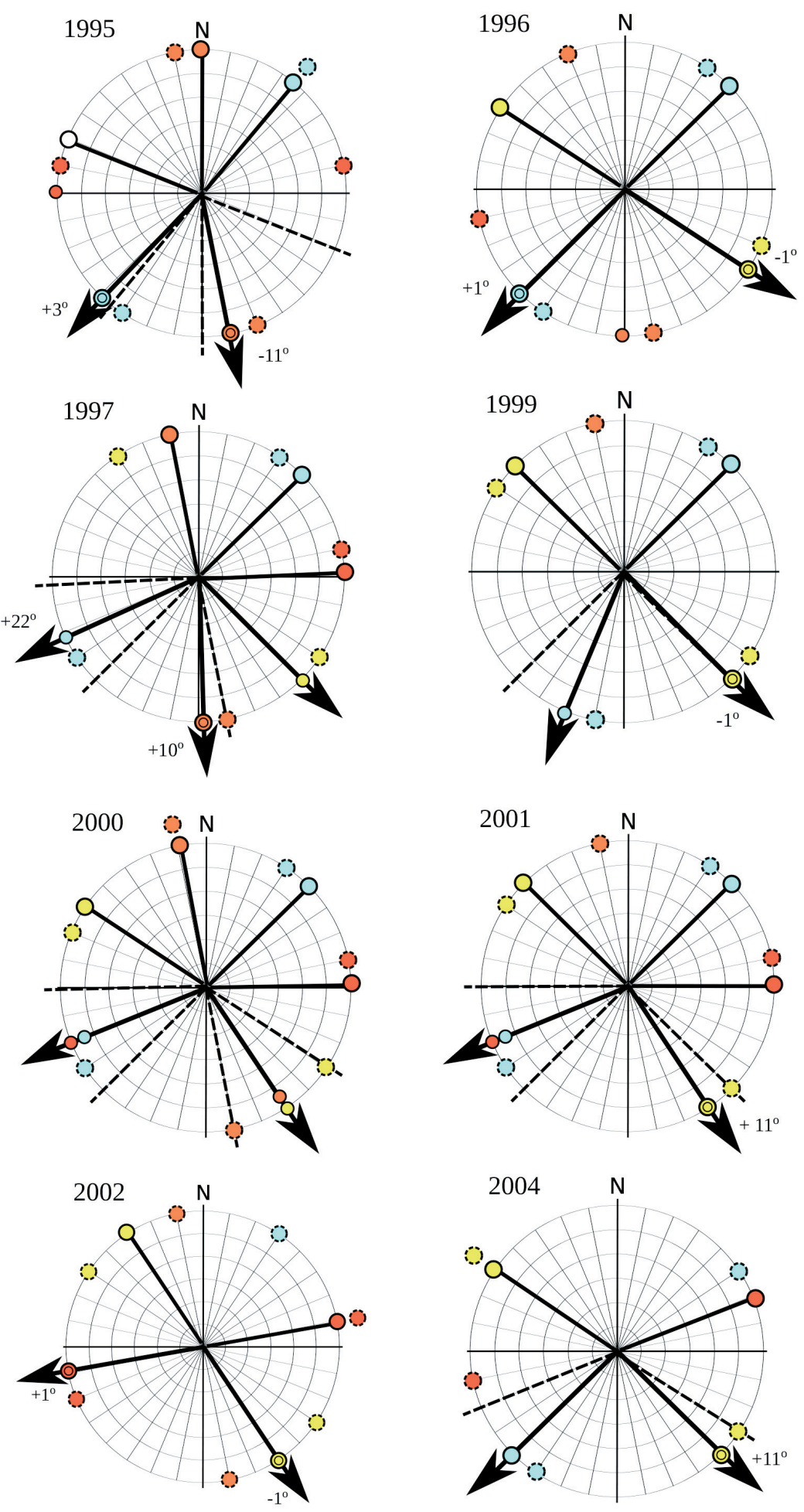

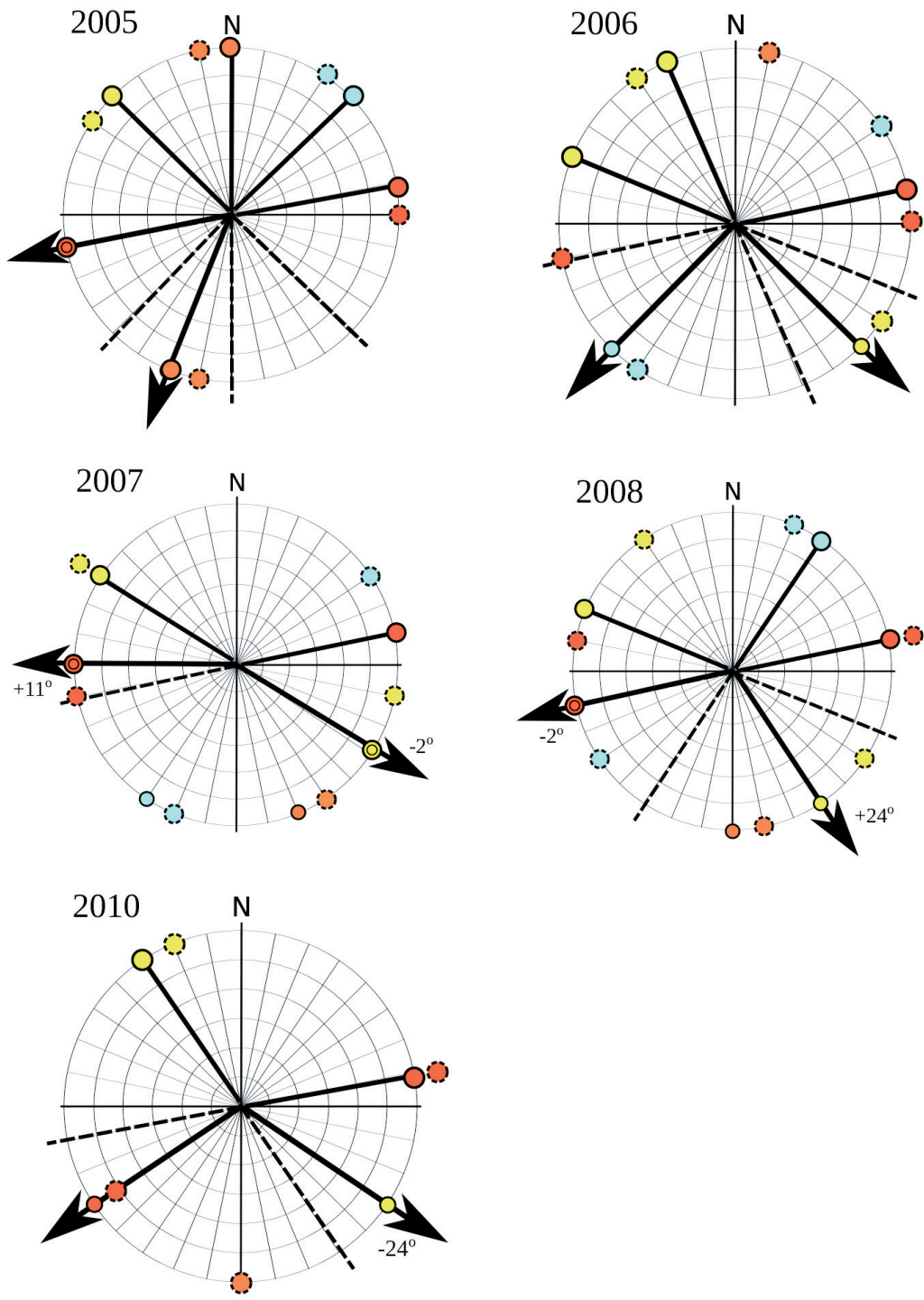

Fig. 5. Axes of headings of different migratory groups estimated directly from yearly (1995-2010) distributions of headings (broken-line circles) and using the calculation procedure (solid-line circles). Calculated deviations from linearity of arrival-departure headings at each location are given in degrees.

Estimations of total and yearly headings of the YELLOW and ORANGE groups are in full agreement, while calculated headings differ from them by one sector. Generally, average deviations from axiality in all variants of the procedures are very small and not significant (Tables 1 and 2). In about half of tested axes, differences between arrival/departure tracks were within only one sector. Thus, the earlier supposition that arrival and departure headings are generally axial seems to be confirmed. However, this does not mean that the rule applies to all species at every location on 

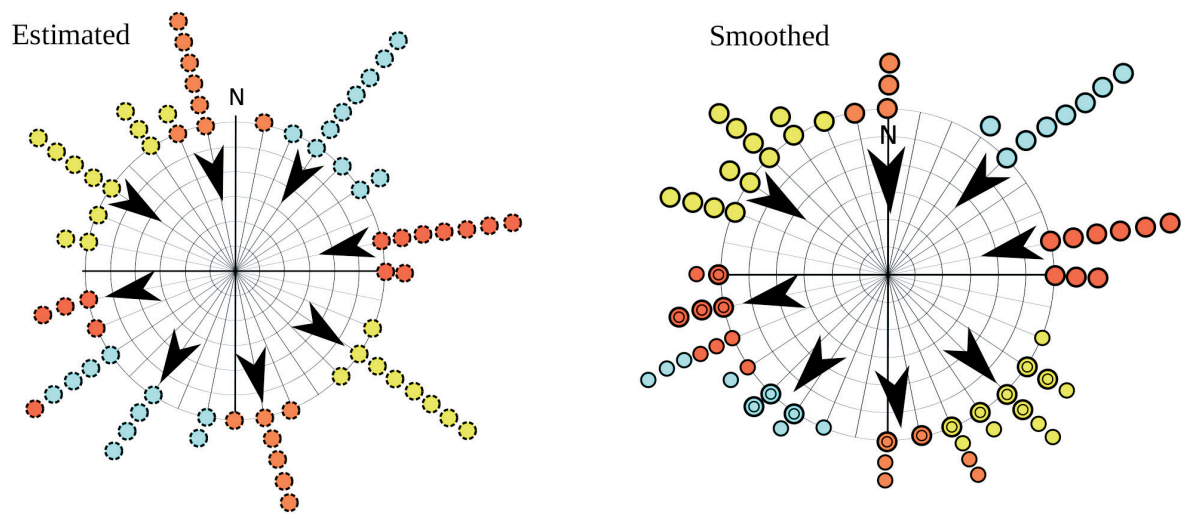

Fig. 6. Summary of yearly distributions of headings (as in Fig. 5). Left panel - directly estimated; right panel - estimated by the calculation procedure.
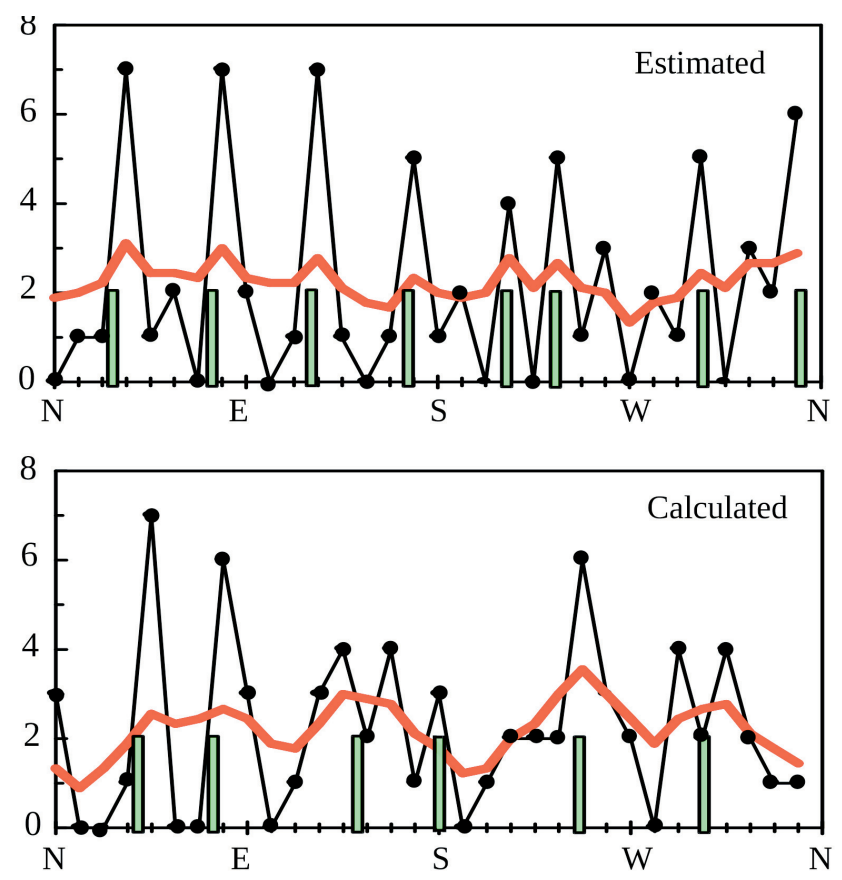

Fig. 7. Data from Fig. 6 in linear graphic form: dots, thin line - number of yearly headings in sector, Thick line - data smoothed by the five-sector moving average, bars - set of estimated directions.

the migration route. It may be that at sites where the migration stream changes its general direction (e.g. at edges of the migratory barrier), the arrival and departure headings could significantly deviate from axiality. This is one of the problems for future studies. 


\section{Table 3}

Distribution of yearly vectors (estimated and calculated) in sectors (numbered clockwise from the north) with peak numbers (X) for groups of migrants in relation to total estimated heading locations (V).

\begin{tabular}{|c|c|c|c|c|c|}
\hline \multirow{3}{*}{ Sectors } & \multirow{3}{*}{$\begin{array}{l}\text { Total vectors } \\
\text { estimated } \\
\text { (Location) }\end{array}$} & \multicolumn{4}{|c|}{ Yearly vectors } \\
\hline & & \multicolumn{2}{|c|}{ estimated } & \multicolumn{2}{|c|}{ calculated } \\
\hline & & $N$ vectors & Location & $N$ vectors & Location \\
\hline 1 & & 0 & & 3 & $\mathrm{X}$ \\
\hline 2 & & 1 & & 0 & \\
\hline 3 & & 1 & & 0 & \\
\hline 4 & $\mathrm{~V}$ & 7 & $\mathrm{X}$ & 1 & \\
\hline 5 & & 1 & & 7 & $\mathrm{X}$ \\
\hline 6 & & 2 & & 0 & \\
\hline 7 & & 0 & & 0 & \\
\hline 8 & $\mathrm{~V}$ & 7 & $\mathrm{X}$ & 6 & $\mathrm{X}$ \\
\hline 9 & & 2 & & 3 & \\
\hline 10 & & 0 & & 0 & \\
\hline 11 & & 1 & & 1 & \\
\hline 12 & $\mathrm{~V}$ & 7 & $\mathrm{X}$ & 3 & \\
\hline 13 & & 1 & & 4 & $\mathrm{X}$ \\
\hline 14 & & 0 & & 2 & \\
\hline 15 & & 1 & & 4 & \\
\hline 16 & $\mathrm{~V}$ & 5 & $\mathrm{X}$ & 1 & $\mathrm{X}$ \\
\hline 17 & & 1 & & 3 & \\
\hline 18 & & 2 & & 0 & \\
\hline 19 & & 0 & & 1 & \\
\hline 20 & $V$ & 4 & $\mathrm{X}$ & 2 & \\
\hline 21 & & 0 & & 2 & \\
\hline 22 & & 5 & $\mathrm{X}$ & 2 & \\
\hline 23 & & 1 & & 6 & $\mathrm{X}$ \\
\hline 24 & $\mathrm{~V}$ & 3 & & 3 & \\
\hline 25 & & 0 & & 2 & \\
\hline 26 & & 2 & & 0 & \\
\hline 27 & & 1 & & 4 & \\
\hline 28 & $\mathrm{~V}$ & 5 & $\mathrm{X}$ & 2 & \\
\hline 29 & & 0 & & 4 & $\mathrm{X}$ \\
\hline 30 & & 3 & & 2 & \\
\hline 31 & & 2 & & 1 & \\
\hline 32 & $\mathrm{~V}$ & 6 & $\mathrm{X}$ & 1 & \\
\hline
\end{tabular}

\section{Quantitative aspects of the heading patterns}

The calculation procedure in the analysis of the heading pattern can be used to study the approximate 'powers' of the heading vectors, which are quantitative estimations of the share of individuals heading in separate directions in the sample of birds (Tables 4 and 5). The power of the heading vector contains relative values of three vectors assigned to that heading from the calculated 32-sector heading distribution. Table 4 contains values for arrival and departure vectors, while Table 5 presents values for axes of headings. Within each table the yearly percentage shares for migration 
groups (colour groups) are defined as a number Index for each group. The total is the sum of these group indices, while the Average (Yearly) Index shows how much of the basic heading distribution was included in the number validation procedure. In Table 4 , the arrival heading values include on average $29.0 \%$ of the original yearly distribution, and the departure heading values include $30.2 \%$. The Total for arrival/departure includes $59.2 \%$ of the original vector powers. For Table 5, the Total is $67.3 \%$. The final number Group Index (\%) values (for migratory groups) are the average Yearly Group Indices expressed as a percentage of the Total Index.

Table 4

Number indices of arrivals and departures of different groups of migrants as shown by migratory headings using the calculation procedure. Group Index \% percentage share within Total average index for arrivals and for departures.

\begin{tabular}{|c|c|c|c|c|c|c|}
\hline Arrival & $R E D$ & $B L U E$ & $R E D+B L U E$ & ORANGE & YELLOW & Total \\
\hline 1995 & 0 & 20.0 & 20.0 & 5.8 & 26.0 & 51.8 \\
\hline 1996 & 0 & 13.5 & 13.5 & 0 & 16.7 & 30.2 \\
\hline 1997 & 12.8 & 13.8 & 26.6 & 5.5 & 0 & 32.1 \\
\hline \multicolumn{7}{|l|}{1998} \\
\hline 1999 & 0 & 16.9 & 16.9 & 0 & 9.1 & 26.0 \\
\hline 2000 & 12.1 & 12.6 & 24.7 & 7.0 & 7.0 & 38.7 \\
\hline 2001 & 8.8 & 15.1 & 23.9 & 0 & 9.4 & 33.3 \\
\hline 2002 & 8.2 & 0 & 8.2 & 0 & 12.1 & 20.3 \\
\hline \multicolumn{7}{|l|}{2003} \\
\hline 2004 & 10.7 & 0 & 10.7 & 0 & 7.5 & 18.2 \\
\hline 2005 & 18.9 & 0 & 18.9 & 7.9 & 8.1 & 34.9 \\
\hline 2006 & 15.7 & 0 & 15.7 & 0 & 10.6 & 26.3 \\
\hline 2007 & 5.8 & 0 & 5.8 & 0 & 15.4 & 21.2 \\
\hline 2008 & 7.4 & 6.7 & 14.1 & 0 & 12.9 & 27.0 \\
\hline \multicolumn{7}{|l|}{2009} \\
\hline 2010 & 11.0 & 0 & 11.0 & 0 & 6.4 & 17.4 \\
\hline Average Index & 8.6 & 7.6 & 16.1 & 2.0 & 10.9 & 29.0 \\
\hline$S D$ & 5.7 & 7.5 & 6.7 & 3.1 & 6.0 & \\
\hline$V \%$ & 66.9 & 99.6 & 41.6 & 152.3 & 55.2 & \\
\hline Group Index \% & 29.5 & 26.1 & 55.6 & 6.9 & 37.4 & \\
\hline Departure & $R E D$ & $B L U E$ & $R E D+B L U E$ & ORANGE & YELLOW & Total \\
\hline 1995 & 16.4 & 3.0 & 19.4 & 4.7 & 0 & 24.1 \\
\hline 1996 & 0 & 0 & 0 & 8.8 & 15.5 & 24.3 \\
\hline 1997 & 18.3 & 0 & 18.3 & 9.0 & 8.7 & 36.0 \\
\hline \multicolumn{7}{|l|}{1998} \\
\hline 1999 & 0 & 9.5 & 9.5 & 0 & 19.3 & 28.8 \\
\hline 2000 & 10.5 & 0 & 10.5 & 0 & 12.7 & 23.2 \\
\hline 2001 & 8.5 & 0 & 8.5 & 0 & 12.4 & 20.9 \\
\hline 2002 & 13.6 & 0 & 13.6 & 0 & 13.2 & 26.8 \\
\hline 2003 & & & & & & \\
\hline
\end{tabular}


Table 4. cont.

\begin{tabular}{|c|c|r|r|r|r|r|}
\hline 2004 & 0 & 13.9 & 13.9 & 0 & 19.9 & 33.8 \\
\hline 2005 & 3.6 & 5.5 & 9.1 & 0 & 17.9 & 27.0 \\
\hline 2006 & 0 & 9.2 & 9.2 & 0 & 15.7 & 24.9 \\
\hline 2007 & 6.3 & 13.6 & 19.9 & 11.1 & 13.6 & 44.6 \\
\hline 2008 & 13.8 & 0 & 13.8 & 9.2 & 13.3 & 36.3 \\
\hline 2009 & & & & & & \\
\hline 2010 & 0 & 17.4 & 17.4 & 16.2 & 8.5 & 42.1 \\
\hline Average Index & $\mathbf{7 . 0}$ & $\mathbf{5 . 5}$ & $\mathbf{1 2 . 5}$ & $\mathbf{4 . 5}$ & $\mathbf{1 3 . 1}$ & $\mathbf{3 0 . 2}$ \\
\hline SD & $\mathbf{6 . 7}$ & $\mathbf{6 . 2}$ & $\mathbf{6 . 5}$ & $\mathbf{5 . 4}$ & $\mathbf{5 . 1}$ & \\
\hline $\boldsymbol{V} \%$ & $\mathbf{9 5 . 2}$ & $\mathbf{1 1 1 . 3}$ & $\mathbf{5 1 . 5}$ & $\mathbf{1 1 9 . 6}$ & $\mathbf{3 8 . 6}$ & \\
\hline Group Index \% & $\mathbf{2 3 . 2}$ & $\mathbf{1 8 . 3}$ & $\mathbf{4 1 . 5}$ & $\mathbf{1 5 . 0}$ & $\mathbf{4 3 . 5}$ & \\
\hline
\end{tabular}

Table 5

Number indices for axes (arrivals plus departures) of different groups of migrants as shown by migratory headings using the calculation procedure. Group Index \% percentage share within total average index for axes. Below -

ratio of departure index to arrival index.

\begin{tabular}{|c|c|c|c|c|c|c|}
\hline Axes & $R E D$ & $B L U E$ & $R E D+B L U E$ & ORANGE & YELLOW & Total* \\
\hline 1995 & 16.4 & 23.0 & 39.4 & 10.5 & 26.0 & 75.9 \\
\hline 1996 & 0 & 13.5 & 13.5 & 8.8 & 32.2 & 54.5 \\
\hline 1997 & 31.1 & 13.8 & 44.9 & 14.5 & 8.7 & 68.1 \\
\hline \multicolumn{7}{|l|}{1998} \\
\hline 1999 & 0 & 26.4 & 26.4 & 0 & 28.4 & 54.8 \\
\hline 2000 & 22.6 & 12.6 & 35.2 & 7.0 & 19.7 & 61.9 \\
\hline 2001 & 17.3 & 15.1 & 32.4 & 0 & 21.8 & 54.2 \\
\hline 2002 & 21.8 & 0 & 21.8 & 0 & 25.3 & 47.1 \\
\hline \multicolumn{7}{|l|}{2003} \\
\hline 2004 & 10.7 & 13.9 & 24.6 & 0 & 27.4 & 52.0 \\
\hline 2005 & 22.5 & 5.5 & 28.0 & 7.9 & 26.0 & 61.9 \\
\hline 2006 & 15.7 & 9.2 & 24.9 & 0 & 26.3 & 51.2 \\
\hline 2007 & 12.1 & 13.6 & 25.7 & 11.1 & 29.0 & 65.8 \\
\hline 2008 & 21.2 & 6.7 & 27.9 & 9.2 & 26.2 & 63.3 \\
\hline \multicolumn{7}{|l|}{2009} \\
\hline 2010 & 11.0 & 17.4 & 28.4 & 16.2 & 14.9 & 59.5 \\
\hline Average Index & 15.6 & 13.1 & 28.7 & & 24.0 & 67.3 \\
\hline$S D$ & 8.6 & 6.7 & 7.8 & 5.7 & 6.1 & \\
\hline$V \%$ & 55.0 & 51.1 & 27.1 & 86.9 & 25.4 & \\
\hline Group Index \% & 29.5 & 26.1 & 55.6 & 6.9 & 37.4 & \\
\hline Departure/Arrival & 0.82 & 0.73 & 0.78 & 2.25 & 1.21 & \\
\hline
\end{tabular}

When presenting values for the RED and BLUE groups it was taken into account that the yearly variation of departures in heading directions obtained for these groups was relatively wide (see Fig. 6 and Table 3), so that the calculations of number indices were 
less precise than in other groups. Thus, in Tables 4 and 5 a column combining $R E D$ and $B L U E$ values was added.

In a number of earlier papers (e.g. Formella and Busse 2002, Ściborska and Busse 2004, Stępniewska et al. 2011, Hnatyna and Busse 2010, more discussed in Busse 2017) it can be seen that when the lengths of vectors representing the same axis are compared, the ratio of departure to arrival headings is highly varied. This suggests that in the special cage conditions, birds representing different axes of headings behave differently in terms of whether they show an arrival or a departure heading. The problem is illustrated at the bottom of Table 5 and in Figure 8 using the data from the calculation procedure in the present work. There are visible differences in the ratio of arrival and departure heading indices. It seems that long-distance Blackcaps (ORANGE and YELLOW groups) are more likely to show departure headings than the short-distance BLUE and RED groups. This is another interesting suggestion for further studies on data from other locations and other species.

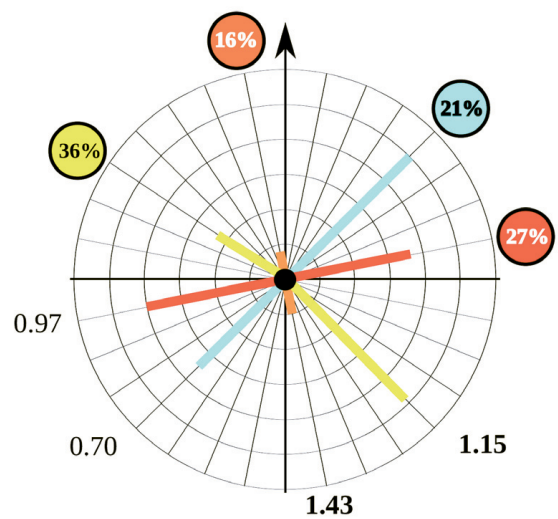

Fig. 8. Estimated heading directions and frequencies of defined migratory groups (percentage shares of axes) and number relations between departure headings and arrival headings of migratory groups.

Having both the heading direction and the 'powers' of the vectors, the local pattern of migration can be presented as in Figure 9, where new, quantitatively treated headings provide better information about the value of the migration streams identified at that spot. After further work using data from more study sites, it will be possible to estimate the relative values of migration streams for separate species.

The results from the calculation procedure could also be used to estimate the longterm number dynamics of specific migratory populations. Long-term trend dynamics at permanently operating ringing sites (e.g. Operation Baltic, SEEN, Rybatchy, Helgoland, Falsterbo, Ottenby and others) for species caught/observed on migration are estimated at the species level. Since at most sites counted totals include individuals belonging to more than one migratory population, the values contain a hidden composition of the population trends of the populations included. It is very well documented that long-term number dynamics can be markedly different at different ringing sites, even those situated close together (e.g. Busse and Halastra 1981, Busse 1990). 

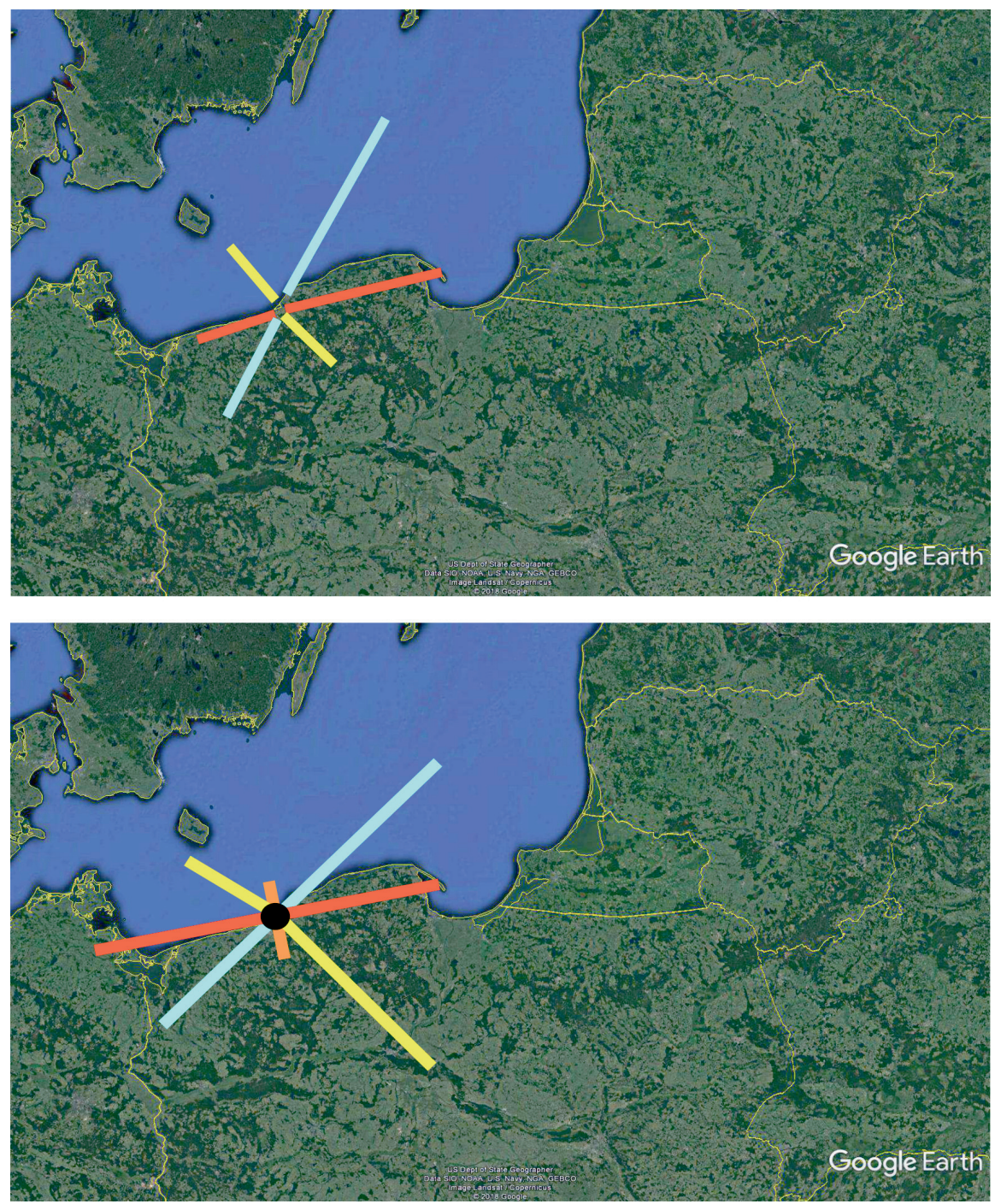

Fig. 9. Comparison of the general heading pattern of passerines at the Bukowo/Kopań site (upper panel - after Fig. 8 in Busse 2019; lengths of lines do not reflect numbers) and Blackcap heading pattern (lower panel - Fig. 8 here; lengths of lines according to estimated number indices).

Knowledge about individual population trends becomes accessible only when data from orientation cages are analysed. The estimated quantitative indices of headings of migratory groups, discussed above, make it possible to present some interesting, though preliminary patterns.

We can separately study arrival and departure indices over the years. If the local relation between arrival and departure headings for the location is stable over the years of the study, the results should be the same for arrival and departure headings of the same migratory group. Figure 10 shows patterns observed for defined migratory 

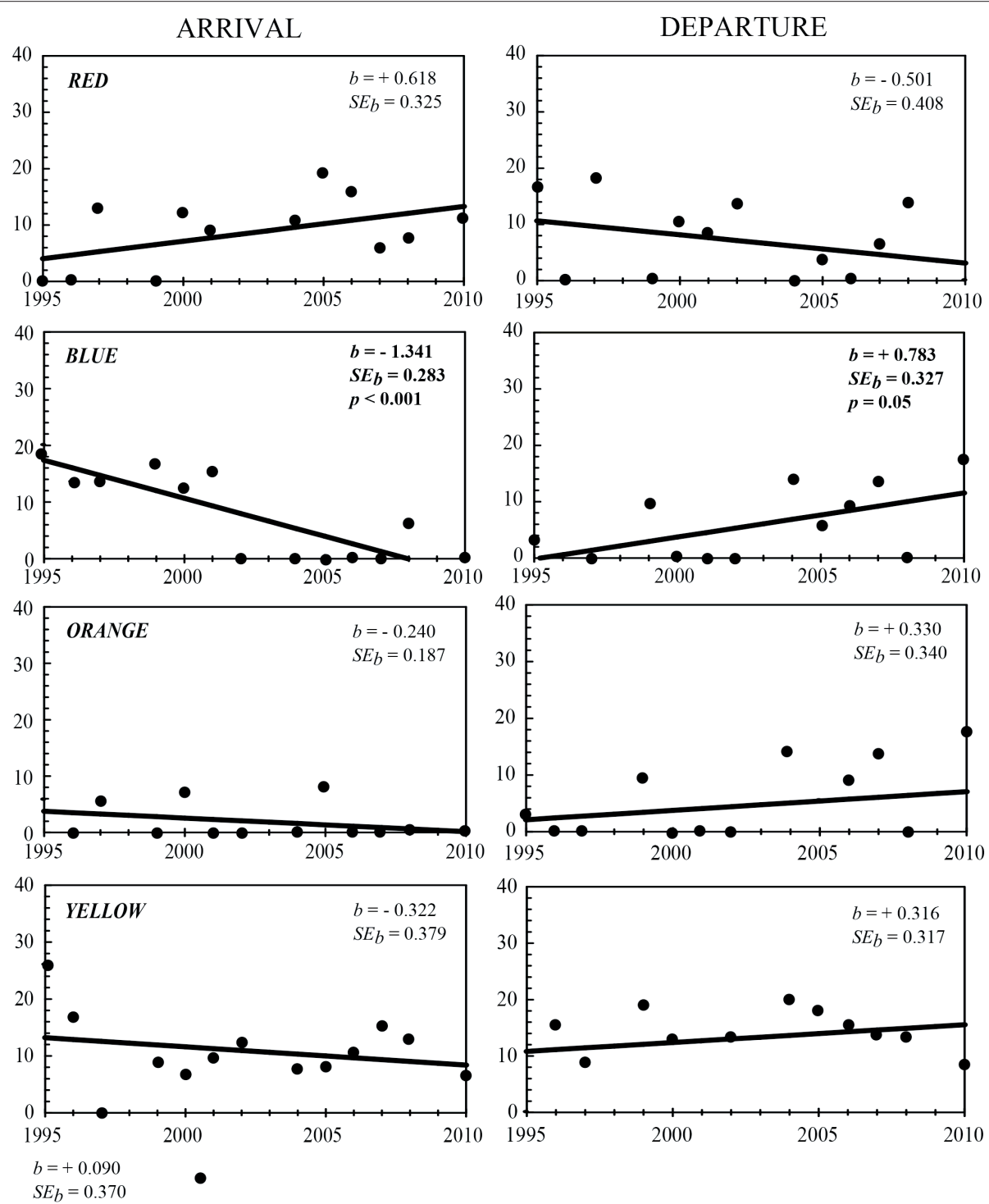

Fig. 10. Long-term trends of numbers of headings on arrival and departure for different groups of migrating Blackcaps. Regression parameters $b$ and $S E_{b}$ are given. Statistically significant trends for the BLUE group $(p<0.001$ and $p=0.05)$ are shown in bold.

groups. In the RED, ORANGE and YELLOW groups, the regression of yearly number indices against the year is in agreement, but while for RED and YELLOW the trend is negative (but not significant), the trends for both arrival and departure headings are significantly $(p=0.05)$ positive. A special and surprising situation is found in the $B L U E$ group: the trend is significantly $(p=0.05)$ negative for arrivals, while it is significantly $(p<0.05)$ positive for departures, which means that the difference is highly significantly different $(p=0.002)$. Hence in this case the heading mechanism seems to be in evolution over the years of the study (1995-2010). It is difficult to speculate 
on the mechanism/reasons for that. This is another question to be solved in this field of study. When we add the data at the level of the regression of the total size of the group against time, the $B L U E$ group seems to show a negative regression line (Fig. 11), while those of the others are more or less neutral. However, comparison of the regression coefficients $b$ for migrating groups shows significant differences between them (Table 6). There is substantial differentiation between the YELLOW group and the others, while the RED and BLUE groups are the most similar (see $t$-values for arrivals in Table 6). It could be pointed out that the RED and BLUE groups have adjacent headings, as do the BLUE and ORANGE groups. The YELLOW group is the most 'independent'.
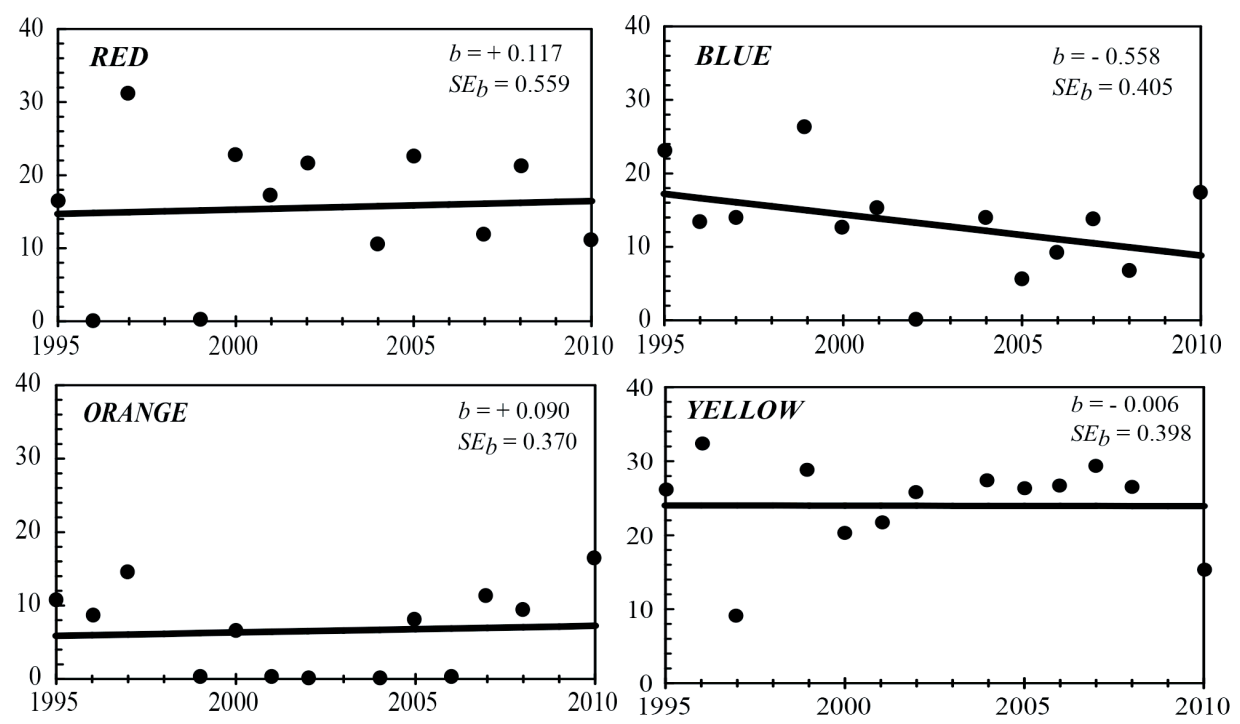

Fig. 11.Long-term trends of numbers of headings at axes for different groups of migrating Blackcaps. Regression parameters $b$ and $S E_{b}$ are given.

Table 6

Relations between migratory groups for long-term (1995-2010) regression of the number indices according to $t$-test of the regression coefficient $b$. Significant differences given in bold.

Arrivals

\begin{tabular}{|l|c|c|c|}
\hline \multicolumn{1}{|c|}{$p$-values } & BLUE & ORANGE & YELLOW \\
\hline RED & 0.70 & 0.33 & $\mathbf{0 . 0 1}$ \\
\hline BLUE & $\mathrm{x}$ & 0.23 & $\mathbf{0 . 0 5}$ \\
\hline ORANGE & & $\mathrm{x}$ & $\mathbf{0 . 0 0 2}$ \\
\hline
\end{tabular}

\begin{tabular}{|l|c|c|c|}
\hline \multicolumn{1}{|c|}{$t$-values } & BLUE & ORANGE & YELLOW \\
\hline$R E D$ & 0.38 & 1.00 & $\mathbf{2 . 6 6}$ \\
\hline$B L U E$ & $\mathrm{x}$ & 1.24 & $\mathbf{1 . 9 8}$ \\
\hline ORANGE & & $\mathrm{x}$ & $\mathbf{3 . 5 1}$ \\
\hline
\end{tabular}


Departures

\begin{tabular}{|l|c|c|c|}
\hline \multicolumn{1}{|c|}{$p$-values } & BLUE & ORANGE & $Y E L L O W$ \\
\hline$R E D$ & 0.56 & $\mathbf{0 . 0 1}$ & 0.30 \\
\hline BLUE & $\mathrm{x}$ & & 0.66 \\
\hline ORANGE & & $\mathrm{x}$ & $<\mathbf{0 . 0 0 1}$ \\
\hline
\end{tabular}

\begin{tabular}{|l|c|c|c|}
\hline \multicolumn{1}{|c|}{$t$-values } & BLUE & ORANGE & YELLOW \\
\hline$R E D$ & 0.59 & $\mathbf{2 . 6 1}$ & 1.04 \\
\hline BLUE & $\mathrm{x}$ & & 0.44 \\
\hline ORANGE & & $\mathrm{x}$ & $\mathbf{4 . 1 7}$ \\
\hline
\end{tabular}

\begin{tabular}{|c|c|c|c|}
\hline \multicolumn{4}{|l|}{ Axes } \\
\hline$p$-values & $B L U E$ & ORANGE & YELLOW \\
\hline$R E D$ & 0.42 & 0.008 & 0.004 \\
\hline$B L U E$ & $\mathrm{x}$ & 0.002 & 0.01 \\
\hline ORANGE & & $\mathrm{x}$ & $<0.001$ \\
\hline$t$-values & $B L U E$ & ORANGE & YELLOW \\
\hline$R E D$ & 0.83 & 2.87 & 3.18 \\
\hline$B L U E$ & $\mathrm{x}$ & 4.34 & 2.70 \\
\hline ORANGE & & $\mathrm{x}$ & 7.56 \\
\hline
\end{tabular}

Table 7

Relations between migratory groups for long-term (1995-2010) average yearly number indices according to $t$-test. Significant differences given in bold.

$p$-values

\begin{tabular}{|l|c|c|c|}
\hline \multicolumn{1}{|c|}{ Arrivals } & BLUE & ORANGE & YELLOW \\
\hline RED & 0.48 & $\mathbf{0 . 0 3}$ & 0.07 \\
\hline BLUE & $\mathrm{x}$ & 0.16 & 0.08 \\
\hline ORANGE & & $\mathrm{x}$ & 0.85 \\
\hline
\end{tabular}

\begin{tabular}{|l|c|c|c|}
\hline \multicolumn{1}{|c|}{ Departures } & BLUE & ORANGE & YELLOW \\
\hline$R E D$ & $\mathbf{0 . 0 2}$ & 0.13 & 0.13 \\
\hline BLUE & $\mathrm{x}$ & 0.35 & 0.32 \\
\hline ORANGE & & $\mathrm{x}$ & $\mathbf{0 . 9 8}$ \\
\hline
\end{tabular}

\begin{tabular}{|c|c|c|c|}
\hline Axes & $B L U E$ & ORANGE & YELLOW \\
\hline$R E D$ & 0.76 & 0.48 & 0.38 \\
\hline$B L U E$ & $\mathrm{X}$ & 0.12 & 0.12 \\
\hline ORANGE & & $\mathrm{x}$ & 0.35 \\
\hline \multicolumn{4}{|l|}{$t$-values } \\
\hline Axes & $B L U E$ & ORANGE & YELLOW \\
\hline$R E D$ & 0.98 & 0.04 & 0.32 \\
\hline$B L U E$ & $\mathrm{x}$ & 1.18 & 1.22 \\
\hline ORANGE & & $\mathrm{x}$ & 0.40 \\
\hline
\end{tabular}


Another aspect of group comparisons is the number relations between groups in yearly samples (average yearly indices - Tables 4 and 5). In this parameter, the RED and ORANGE groups seem to differ most in terms of arrivals (Table 7), and RED and $B L U E$, surprisingly, in the case of departures. The axial numbers seem not to be especially differentiated. The yearly number indices for different groups can fluctuate according to the population size dynamics of migrating populations. This may depend on the effectiveness of breeding in the various source areas where the birds originate. Thus, a better and positive correlation could be expected between populations migrating from neighbouring breeding areas. In Table 8, the correlations between $O R A N G E, R E D$ and $B L U E$ are positive but low, suggesting neighbouring source areas, while the $Y E L L O W$ population shows a negative, even significantly, correlation with the others, indicating that its breeding area may be quite separated from the others. However, as the case data are unique, further work on other species and at other study sites is needed for a reasonable discussion of the problem.

Table 8

Correlations between migratory groups for yearly (1995-2010) number indices. Pearson's correlation $r$. Significant correlations given in bold.

\begin{tabular}{|c|c|c|c|}
\hline Axes & $B L U E$ & ORANGE & YELLOW \\
\hline$R E D$ & -0.52 & 0.22 & -0.62 \\
\hline$B L U E$ & $\mathrm{x}$ & 0.14 & 0.04 \\
\hline$R E D+B L U E$ & & 0.37 & -0.73 \\
\hline ORANGE & & $\mathrm{x}$ & -0.47 \\
\hline
\end{tabular}

\section{CONCLUSIONS}

1. The hypothesis that the arrival/departure heading axes are generally linear is accurate to within about one $10^{\circ}$ sector, at least in the case of the Blackcap. This is coherent with impressions from other known data sets. However, this does not mean that the rule always applies to all species at every location on the migration route. This problem should be studied in more detail in the future.

2. Estimating arrival and departure headings makes it possible to define migratory groups (populations) passing the study site. The direct heading estimation procedure seems to be more sensitive in identifying migratory groups than the calculation procedure.

3. The calculation procedure can be used to estimate some quantitative properties of the headings of migratory groups and define some interesting, though preliminary, number patterns of local migratory movements.

4. Number relations between birds demonstrating the arrival and departure headings of the migratory group seem to be an interesting parameter for studying the distance of migration of groups within a species, and possibly between species. This is the next interesting problem that the cage tests could to be used to solve in the future.

5. Knowledge of the trends of individual populations passing a given site becomes accessible only when the analysis of data from orientation cages is used. The esti- 
mated quantitative indices discussed above could be helpful in presenting the general migratory pattern of the species on a geographical scale.

\section{ACKNOWLEDGEMENTS}

I would like to express my deep gratitude to tens of participants (both ornithologists and volunters) of the field work at the Bukowo/Kopan ringing station in years 1995-2010 for their input into collection of the data used.

\section{REFERENCES}

Adamska K., Filar M. 2005. Directional preferences of the Chiffchaff (Phylloscopus collybita) and the Robin (Erithacus rubecula) on autumn migration in the Beskid Niski Mountains (S Poland). Ring 27, 2: 159-176.

Adamska K., Rosińska K. 2006. Directional preferences of the Robin (Erithacus rubecula) and the Blackcap (Sylvia atricapilla) during autumn migration at Arosio (N Italy) in 2005. Ring 28, 2: 101-111.

Busse P. 1990. Studies of long-term population dynamics based on ringing data. Ring 13, 1-2: 221-234.

Busse P. 1995. New technique of a field study of directional preferences of night migrants. Ring 17, 1-2: 97-116.54

Busse P. 2017. Busse's flat orientation cage vs. Emlen's funnel - compatibility, differences and conclusions. Ring 39: 3-21.

Busse P. 2018. Estimation of local heading patterns of nocturnal migrants using orientation cages. Ring 40: 31-58.

Busse P. 2019. Estimation of the autumn migration pattern of passerines within the SE European flyway by orientation cage tests. Ring 41: 43-64.

Busse P., Gavrilov V. M., Ivliev V., Nowakowski J. K. 2001. Differentiation of directional preferences of some nocturnal migrants on autumn migration across the central and eastern Europe. Ring 23, 1-2: 119-130.

Busse P., Halastra G. 1981. The autumn migration of birds on the Polish Baltic sea coast. Acta orn. 18, 3: 1-122.

Busse P., Trocińska A. 1999. Evaluation of orientation experiment data using circular statistics doubts and pitfals in assumptions. Ring 21, 2: 107-130.

Emlen S.T., Emlen J.T. 1966. A technique of recording migratory orientation of captive birds. Auk 83: $361-367$.

Evans P. R. 1968. Reorientation of passerine night migrants after displacement by the wind. Brit. Birds 61: 281-303.

Formella M., Busse P. 2002. Directional preferences of the Reed Warbler (Acrocephalus scirpaceus) and the Sedge Warbler (A. schoenobaenus) on autumn migration at Lake Druzino (N Poland). Ring 24, 2: 15-29.

Hnatyna O. and Busse P. 2010. Directional preferences, stopover and moult strategies of the Sedge Warbler, Acrocephalus schoenobaenus, at Burullus Lagoon, Northern Egypt. 25 JD International Ornithological Congress, Brasil. DOI: 10.13140/RG.2.2.35958.2464064

Kramer G. 1949. Über Richnungstendenzen bei der nächtlichem Zugungruhe gekäftiger Vögel. In: Ornithologie als Biologische Wissenschaft. Heidelberg.

Muś K. 2005. Bayesian evolution of circular data from bird orientation experiments. Presentation at Cambridge meeting.

Muś K. 2008. Bayesian analysis of the multimodal bird behaviour in orientation cage tests. ISEC-2008 Conference. DOI: 1013140/RG.2.1.4386.8323 
Nowakowski J. K., Malecka A. 1999. Test of Busse's method of studying directional preferences of migrating small Passeriformes. Acta orn. 34: 37-44.

Ożarowska A., Ilieva M., Zehtindjiev P. , Ckesson S., Muś K. 2013. A new approach to evaluate multimodal orientation behaviour of migratory passerine birds recorded in circular orientation cages. Journal of Experimental Biology 216: 4038-4046. DOI: 10.11242/jeb 088757

Ożarowska A., Muś K. 2008. Orientation cage tests (2): Application in bird migration studies - paper. Conf. 6 JD Int. Conf. On Animal Navigation, Royal Institute of Navigation, University of Reading, UK. Volume 2008. DOI: 10.13140/RG.2.1.2034.9928

Ożarowska A., Yosef R. 2004. A comparison of the Emlen funnel and Busse's flat cage for orientation studies. Ring 26, 1: 59-69.

Rosińska K., Adamska K. 2007. Biometrics variation and directional preferences of immature Robins (Erithacus rubecula) caught in northern Italy during autumn migration in 2005. Ring 29, 1-2: 107-120.

Sauer E.G. 1957. Die Sternorientierungnhlih zeihender Grasmucken (Sylvia atricapilla, borin und curruca) Zeit. Tierpsychol. 14: 29-70.

Stępniewska K., El-Hallah A., Busse P. 2011. Migration dynamics and directional preferences of passerine migrants in Azraq (E Jordan) in spring 2008. Ring 33, 1-2: 3-23. DOI: 10.2478/v10050011-0001-9

Ściborska M., Busse P. 2004. Intraseasonal changes in directional preferences of Robins (Erithacus rubecula) caught on autumn migration at Bukowo-Kopan ringing station ( $N$ Poland). Ring 26, 1: 41-58.

Trocińska A., Leivits A., Nitecki Cz., Shydlovsky I. 2001. Field studies of directional preferences of the Reed Warbler (Acrocephalus scirpaceus) and the Sedge Warbler (A. schoenobaenus) on autumn migration along the eastern and southern coast of the Baltic sea and in western Ukraine. Ring 23, 1-2: 109-117.

Zehtindjiev P., Ilieva M., Ożarowska A., Busse P. 2003. Directional behaviour of the Sedge Warbler (Acrocephalus schoenobaenus) studied in two types of orientation cages during autumn migration - a case study. Ring 25, 1-2: 53-63. 